\title{
Selenium enrichment of paddy rice grains in Malaysia
}

\begin{abstract}
A greenhouse trial was carried out with the aim of assessing the Se concentration and $\mathrm{Se}$ uptake in different plant parts especially in rice grains and also the effect of Selenium on rice plant yield and some yield components. The experiment was carried out in a randomized complete block design with three replications. Three rice varieties (MR232, MR219 and MR253) and five rates of sodium selenite (Na2SeO3) including 0, 100, 300, 500 and $700 \mathrm{~g}$ ha-1 were selected. It was observed that leaf, culm and the grain of rice varieties as well as total Se uptake and grain uptake were affected by used Se rates. All the Se levels used in this study have been able to increase Se level in rice grains to be acceptable for human consumption but among the different Se levels supplied, the level of $500 \mathrm{~g}$ ha- 1 of $\mathrm{Se}$ is recommended rate in order to increase Se concentration in grain. Plant dry matter yield, grain yield and yield components were not affected by the different supplied Se concentrations.
\end{abstract}

Keyword: Biofortification; Grain; Rice; Selenium; Yield 